\title{
Gestão pública: desassombrando nossa história
}

Patrus Ananias*

\section{Introdução}

Estamos vivendo no Brasil um importante momento de transição paradigmática, no qual enfrentamos desafios de modo a superar dificuldades que fincaram raízes em nossa história. Nesse sentido, podemos mencionar ao menos duas sombras que por muito tempo têm dificultado o desenvolvimento das potencialidades do nosso país. Uma delas é a questão social, pois não tivemos uma tradição de políticas públicas sociais, diretamente voltadas para os mais pobres. Outra sombra diz respeito à burocracia, mas uma burocracia que paralisa, que se torna sinônimo de entrave, ineficiência e atraso e que aqui diz respeito principalmente a um perigoso processo de burocracia das almas, que conduz ao envelhecimento das práticas e à falta de motivação. Essas questões estão sendo enfrentadas e têm uma interface muito importante e mesmo estratégica com a questão da gestão pública. 
Do ponto de vista histórico, a preocupação em desenvolver uma política de qualidade na área de gestão pública é relativamente recente e evidencia um processo importante de valorização e consolidação de políticas. É também o reflexo de um processo de mobilização em torno da defesa e construção de um ideal de bem comum, que se encontra em uma fase avançada de amadurecimento na sociedade brasileira. Assim, percebemos a importância da realização de um Curso de Especialização em Gestão de Políticas Públicas de Proteção e Desenvolvimento Social, como o elaborado na Escola Nacional de Administração Pública (ENAP). Afinal, dentre os muitos desafios que temos na administração pública brasileira, temos o de qualificar as pessoas para garantir qualidade no planejamento das políticas e no atendimento do público.

Vivenciamos essa dimensão no Ministério do Desenvolvimento Social e Combate à Fome (MDS), onde trabalhamos com uma valorosa equipe, superando dificuldades diárias. Entre contratados, servidores e terceirizados, o Ministério conta com pouco mais de 1.400 funcionários comprometidos na administração e coordenação de 17 programas e no atendimento de uma população estimada em 60 milhões de brasileiros, em todos os 5.564 municípios brasileiros. Essas políticas estão mudando a realidade das pessoas, familias e comunidades pobres atendidas e também a do Brasil, o que dá uma medida da eficiência de uma gestão voltada para fazer mudanças. Também é uma equipe formada com liberdade, pois cada profissional foi integrado a ela por suas qualidades, competência e compromissos com metas e objetivos do Ministério. Esse é um dos exemplos de que temos tido ricas experiências de gestão na administração pública e precisamos encontrar caminhos para aperfeiçoá-las, para superar dificuldades herdadas de um processo histórico penoso, com raízes mais profundas do que podemos imaginar, que ultrapassa a formação da estrutura burocrática. O processo de profissionalização da gestão combate também uma forte cultura política.

Uma análise mais detalhada da história do Brasil vai nos mostrar que acumulamos, tanto no setor público quanto no setor privado, um alto déficit de gestão. É isso que explica o desacerto que aos poucos estamos revertendo. Mas o fato é que o Brasil, ao longo de sua história, não liberou as suas extraordinárias possibilidades e energias seguramente por seus problemas de origem econômica e social que foram encaminhados de forma precária e incompleta por orientações políticas excludentes. Mas com certeza, nesse contexto, os problemas de gestão também contribuíram para impedir nossos desenvolvimentos. E é justamente disso que se trata nessa primeira parte do texto, antes de discutir, na segunda parte, sobre a formação de nossas políticas sociais e seu papel na administração pública e no programa de desenvolvimento do país, mostrando os avanços que já alcançamos nessa área. $\mathrm{Na}$ terceira e última parte, fazse uma breve explanação sobre os desafios que ainda temos pela frente no campo da consolidação das conquistas sociais e na gestão pública nos ajuda nessa tarefa.

\section{Gestão: uma dívida histórica}

O que chamamos de um histórico déficit de gestão no Brasil é uma visão rápida, sucinta, da nossa história do ponto de vista da exclusão social. As duas questões estão intimamente ligadas e têm suas 
origens com a chegada dos colonizadores e a implantação das capitanias hereditárias. Eles dividiram o Brasil em quinze áreas e as distribuíram para doze donatários. Ou seja, todo o litoral brasileiro foi dividido em quinze áreas e os seus donatários tinham poderes públicos e benefícios privados. Começa aí um ponto que consideramos um gargalo na história do Brasil e que guarda uma coincidência muito forte no campo da gestão, da administração, da implantação das políticas públicas, que é essa relação promíscua entre o público e o privado. Os donatários tinham inclusive poderes de condenar à morte os negros, os índios e, segundo as ordenações da época, os "peões" - é importante perceber como as expressões excludentes do século XVI se estenderam por nossa história. Era uma situação dramática. As pessoas ditas "mais gradas" podiam ser deportadas para a África por um prazo de até dez anos. Percebemos aí as funções de poder: Poder Executivo, Judiciário e, ao mesmo tempo, uma relação com a coroa com autorização para iniciar a implantação das benfeitorias, as primeiras plantações de cana, processo de escravidão etc.

Por muito tempo considerei, equivocadamente, que a questão das capitanias fosse uma coisa secundária no Brasil, mas hoje estou convencido de que não foi e aprendi isso com o trabalho de um historiador absolutamente conservador, Francisco Adolfo Varnhagen. Ele foi um historiador do Império que escreveu a primeira grande obra histórica no Brasil, a História Geral do Brasil ${ }^{1}$. Nessa obra fica muito claro que as capitanias hereditárias projetaram a sua sombra, com forte desdobramento na história do país ao longo do século XVII, XVIII, muito mais do que aprendemos na escola, quando nos foi apresentado como uma coisa passageira.
$\mathrm{Na}$ esteira das capitanias hereditárias vieram as sesmarias, extensões enormes de terra sem nenhuma produtividade, começando uma relação de poder e terra. $\mathrm{Na}$ esteira das capitanias, das grandes extensões das sesmarias, vem a questão do coronelismo, do mandonismo, que chega ao século XX com muita força pelo menos até a Revolução de 30, mas com remanescentes até hoje, pois ainda convivemos em vários cantos do Brasil com esse poder

\section{"Uma análise} mais detalbada da bistória do Brasil vai nos mostrar que acumulamos, tanto no setor público quanto no setor privado, um alto déficit de gestão. $\hat{E}$ isso que explica o desacerto que aos poucos estamos revertendo."

dentro do Estado. Essa realidade fez parte de minhas memórias. Durante a minha infância, em Bocaiúva, no norte de Minas, havia um médico dono de muita terra. Quando as pessoas cometiam um crime, como aqueles que tinham os desvarios de matar pessoas, entravam nas terras desse médico e estavam protegidos. A polícia não entrava nas terras desse médico e isso 
acontecia ainda nos anos 1950, 1960. Ou seja, muito recente.

Com isso, vamos ligando os fatos e vendo essa relação entre o público e o privado, com o privado prevalecendo e, muitas vezes, impondo normas dentro do próprio território nacional e dentro do espaço de mando. Estamos vendo essa mesma tragédia hoje na questão do chamado crime organizado (embora considere essa expressão infeliz, pois penso que a organização deve traduzir espaços públicos do Estado e da sociedade e não deveríamos transferir essa qualidade para o universo do crime). Ao mesmo tempo, reflete o reconhecimento da terrível dimensão assumida pelas redes criminosas, pois é o crime que desorganiza tudo, as relações, as possibilidades de crescimento, os valores. E nessa relação, os criminosos se apropriaram de áreas como as favelas. Daí essa situação insólita no Brasil, de ter áreas apropriadas pelo crime, assim como tivemos historicamente pelo mandonismo, disputando a influência do Estado.

Outra herança trágica foi a escravidão. Ela foi abolida tardiamente no Brasil e não incorporou em nada nossos antepassados escravos na vida de direitos e deveres da cidadania. Quando houve a Lei Áurea, os escravos foram abandonados à própria sorte. Pelo contrário, o que se discutia naquele momento era se os proprietários de escravos seriam ou não indenizados pela "perda de sua propriedade". Esse era o debate que demonstra bem a perversidade social da história do Brasil, sem negar as dimensões de luminosidade e de esperança que também tivemos ao longo da mesma história, em vários campos, se constituindo em pontos importantes de tensionamento que contribuíram para a formação de uma dimensão libertária dentro do pensamento brasileiro. Os proprietários não foram indenizados, mas também os escravos não levaram nada. Aquilo que Joaquim Nabuco propunha - fazer a abolição com políticas sociais, reforma agrária, incorporação dos direitos e deveres da nacionalidade, da cidadania, para os nossos antepassados escravos - não ocorreu ${ }^{2}$. Não só com os negros, mas também com os antepassados indígenas, que sofreram um longo e penoso processo de violência e destruição de culturas. Nessa conta inclui-se também a questão da violência contra os pobres, pobres brancos, o sertanejo.

Essa é uma história meio esquecida. No tempo de nossa escola primária, a gente aprendia que a história do Brasil é uma história incruenta. Não podemos negar que há uma dimensão de conciliação na história do Brasil que é importante. Temos a questão da integração, da miscigenação, e não podemos nos esquecer dessa dimensão, para não brigar com Gilberto Freyre, com Mário de Andrade, com Darcy Ribeiro, com muita gente que foi intuindo os aspectos mais anunciadores da nossa formação. Mas a violência contra o sertanejo, essa separação de litoral e sertão, Euclides da Cunha acompanhou em Canudos e ficamos sabendo ${ }^{3}$. Mas também precisamos saber: o que aconteceu no Pará com os "cabanos"? E no Maranhão com os "balaios"? E os "sabinos" da Bahia? E as revoluções, essas não sertanejas, as revoluções pernambucanas de 1817, 1824, a Confederação do Equador? Os "cabanos" também de Pernambuco? Os "praieiros", de 1848? A repressão era brutal. Depois que podemos ler Os Sertões, imaginamos o que aconteceu também nessas outras rebeliões. 


\section{Política social, nossa pauta tardia}

A questão social no Brasil só vai aparecer com certa força a partir de 1930. Até então, só havia uma forte ausência nessa área. Não sem controvérsia, é atribuída ao ex-presidente Washington Luiz a famosa frase de que a questão social é uma questão de política, isso às vésperas da Revolução de 1930. Não se sabe se foi ele quem disse, mas o fato é que essa frase, dita ou não pelo ex-presidente, expressa bem os valores da época. Eu me arrependo de já ter desqualificado, em sala de aula, a Revolução de 30. Uma avaliação equivocada, pois foi um momento importante da história do Brasil, que na época era uma grande propriedade rural, oligárquica e cafeeira. E o Brasil mudou a partir de então. Foi uma época que marcou nossa entrada na Era da Modernidade, com todas as contradições desse nosso processo. Veio o Estado Novo, houve ditadura, repressão e isso é muito ruim. Mas tivemos a Consolidação das Leis Trabalhistas (CLT), em 1943, o fortalecimento do Estado brasileiro. Nessa época o projeto nacional brasileiro começa a se colocar de uma forma mais forte, mais importante, o que se dá nesse contexto contraditório da história, de avanços e recuos. A história não é uma linha rígida; ela comporta idas e vindas, sensibilidades.

Há ainda um dado importante sobre nosso processo de avanços e recuos e sobre o qual falo como uma testemunha: os direitos trabalhistas eram exclusivamente para trabalhador urbano. Os trabalhadores rurais não tinham direitos, era o contrato de adesão. Os trabalhadores tinham de se submeter às condições impostas pelo empregador. Não havia nenhuma norma tutelar, nenhuma norma de proteção. Nem havia jornada máxima de trabalho, salário mínimo, férias, repouso semanal remunerado; $13^{\circ}$, então, nem pensar. Nenhuma norma previdenciária em caso de morte, doença. Era uma situação de total desamparo e que só começa a mudar em meados dos anos 1960, outra de nossas contradições e de nossas idas e vindas. O Estatuto do Trabalhador Rural é de 1963. Mas logo depois vem o golpe de 1964 e o fato é que esse estatuto só começa a chegar no norte de Minas por volta da segunda metade dos anos 1960. Mas os fazendeiros demitiram os trabalhadores das suas terras com medo de ação trabalhista, e foi um momento de fortes processos migratórios para as grandes cidades. Ainda em plena ditadura, justamente em seu período mais duro, durante o governo Médici, é implantado o Funrural. Começa com meio salário mínimo para os trabalhadores rurais, depois vem o Pró-Rural e depois o meio salário mínimo vira salário mínimo integral.

O grande marco nas conquistas sociais vem a partir de um dos processos mais anunciadores de nossa história: a constituinte que levou à Constituição de 5 de outubro de 1988. A "Constituição Cidadã" incorporou setores excluídos até então, como desempregados, crianças, idosos, pobres, comunidades indígenas, quilombolas. Nessa Constituição, a assistência social é posta pela primeira vez no campo das políticas públicas, vinculada à saúde e à previdência, na perspectiva ainda não cumprida entre nós da Seguridade Social. Esse é um desafio e, certamente, o modelo hoje da Seguridade Social tem de ir além e incorporar, por exemplo, a segurança alimentar e nutricional, além de outros direitos que vieram após a Constituição de 88. O direito à alimentação foi integrado à Constituição no início deste ano.

$\mathrm{Na}$ esteira da Constituição vieram avanços importantes, como Sistema Único 
de Saúde (SUS) e o Estatuto da Criança e do Adolescente (ECA). Mais à frente, a Lei Orgânica da Assistência Social (LOAS), editada em 1993. Já nessa época, tivemos a onda neoliberal e houve retrocessos nos avanços vividos pelas políticas sociais. A Constituição de 88 começa a ser duramente atacada e atingida por emendas, mudanças, retrocessos. Felizmente, todos esses ataques não conseguiram atingir o núcleo da Constituição, que continua sendo um texto anunciador. Penso que nosso papel hoje é defender essa Constituição e preservá-la para tentar, a partir dela, avançar em leis complementares e ordinárias.

Já em 1996 tivemos sinais de retomada, com a implantação do Programa de Erradicação do Trabalho Infantil (PETI) e, ainda no final do governo do presidente Fernando Henrique Cardoso, temos a introdução do Bolsa Escola, mesmo que de uma forma localizada, junto com outros programas dispersos, como o Bolsa Alimentação e o Vale Gás. Os programas são instituídos de maneira localizada, não são formalizados juridicamente, não são amparados por lei. Praticamente todos eles são programas estruturados de uma forma infralegal, abaixo da lei, como portarias, decretos. Um desafio com o qual estamos trabalhando até hoje, para formalizar e normatizar todos os programas sociais com vistas a uma consolidação de políticas na área social.

No governo passado, houve uma retomada da questão social de uma forma muito mais vigorosa. A criação do programa Bolsa Família, em outubro de 2003, unifica os programas já existentes e dá uma nova dimensão ao programa de transferência de renda condicionada. O Cadastro Único é organizado e torna-se importante instrumento de gestão de política pública social. Temos a criação do Estatuto do Idoso, que amplia o pagamento do Benefício de Prestação Continuada (BPC), garantindo o direito ao programa a partir dos 65 anos e possibilitando o pagamento para até duas pessoas de uma mesma família, no caso de pessoas idosas.

Em janeiro de 2004, foi criado o Ministério do Desenvolvimento Social e Combate à Fome, que foi um grande momento para a história das políticas sociais. Primeiro, porque aponta na perspectiva da integração das políticas, a questão da intersetorialidade, que, acredito, é um grande desafio. Integramos a Assistência Social, e hoje temos vários programas, o BPC, o programa de Atenção Integral às Famílias (PAIF), que se materializa nos Centros de Referência da Assistência Social (CRAS) e também nos Centros de Referência Especializados da Assistência Social (CREAS). Esses centros viabilizam a integração dos programas com o Programa de Erradicação do Trabalho Infantil (PETI) com as estratégias de prevenção e combate à exploração sexual de crianças e adolescentes e também com programas de outras áreas. Na segurança alimentar, temos o Programa de Aquisição de Alimentos da Agricultura Familiar (PAA), que estimula a produção interna da agricultura familiar, integramos equipamentos que favorecem o acesso ao alimento, como os restaurantes populares, as cozinhas comunitárias, os bancos de alimentos e agora as feiras e mercados populares que possibilitam a relação direta do produtor com o consumidor, combatendo a ação dos atravessadores e dos especuladores. E no centro, integrando e dando consistência ampla a essas políticas, o Bolsa Família. É muito importante compreender essa posição do Bolsa Família porque ele não é um programa isolado e, justamente por isso, 
seus resultados são tão positivos. O Bolsa Familia está inserido nessa rede de proteção e promoção social que, além da integração entre os programas do MDS, estamos expandindo para a integração também com a saúde, a educação e com programas que integram positivamente no processo emancipatório das famílias, como o Luz para Todos, e outros desenvolvidos na linha da inclusão produtiva, capacitação profissional, geração de trabalho e renda.

O orçamento do Ministério do Desenvolvimento Social e Combate à Fome, para 2010, foi de R \$38,9 bilhões. Diante da dívida histórica que o Brasil acumulou, pode não ser muito. Mas se consideramos o que foi investido antes, é uma mudança fundamental, é uma mudança de paradigma. É importante observar essa questão do orçamento, porque direcionar recursos desse montante para os pobres, para os trabalhadores de baixa renda, pessoas idosas, pessoas portadoras de deficiência, pobres, agricultores familiares, é uma mudança de rumo, principalmente em um país com a trajetória como a nossa. Sabemos que temos de avançar ainda mais, mas é um parâmetro novo e provocou reações no início. Essa reação foi muito clara durante a crise do Bolsa Família, em 2004, quando o programa foi duramente criticado por setores da sociedade brasileira. Naquela época, muitos diziam que o governo gastava em demasia na área social e que a solução do problema social brasileiro seria investimento e crescimento econômico. Mas sabemos que isso não é verdade. No século XX, o país cresceu muito e talvez tenhamos sido um dos países que mais cresceu economicamente nesse período. Mas crescemos e não distribuímos renda. Crescemos mas não implementamos políticas sociais, não consolidamos uma rede nacional de proteção e promoção social, não priorizamos os pobres e, agora, estamos descobrindo que a questão social, as políticas sociais são boas inclusive para promover o crescimento econômico.

Uma coisa que limita muito o Brasil é a concepção do dualismo, a cultura do "ou isto ou aquilo”. Alceu Amoroso Lima dizia: "O Brasil tem de aprender a superar a disjuntiva 'ou' pela conjuntiva 'e"'. Eu concordo. Acredito que a gente sempre

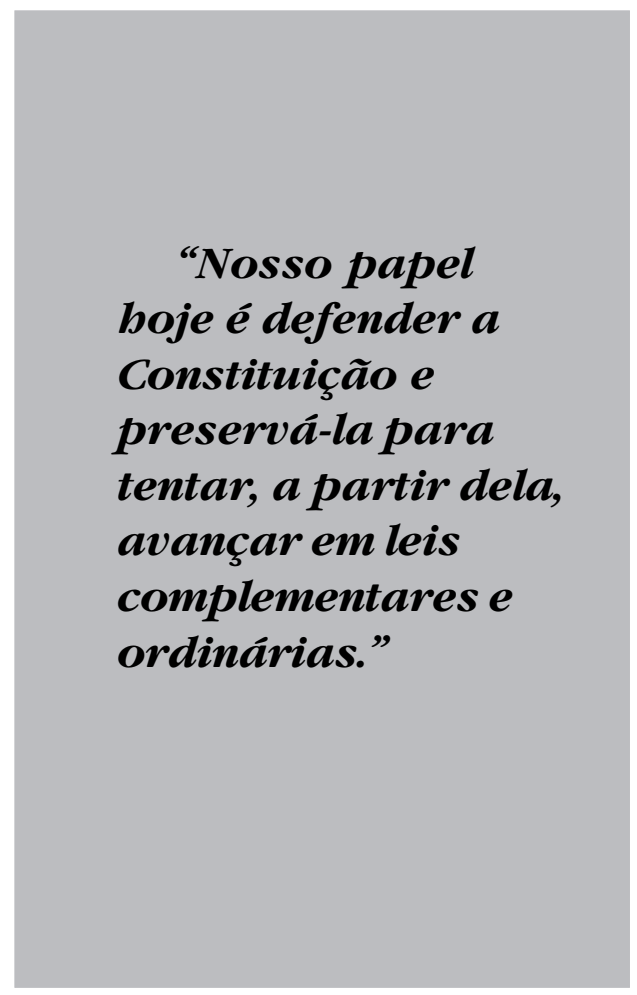

pode acrescentar mais. Com muita passividade, no Brasil, formulamos equações de exclusão reiteradas vezes: ou econômico ou social, remetendo à fórmula, comprovadamente ineficiente, de fazer o bolo crescer para depois dividir. Agora, estamos descobrindo as políticas sociais. Elas têm a sua dimensão ética e humanitária de garantir o direito à vida, o direito à alimentação, à dignidade humana, 
preservar vínculos, valores familiares, comunitários, culturais, dar esse sentimento de pátria, de pertencimento. Mas elas têm também uma dimensão econômica, pois os pobres estão comprando e fazendo o país crescer. Estamos revisando os sonhos de Celso Furtado e tantos outros de criar um mercado interno e poderoso no Brasil, colocar os pobres também para comprar, consumir bens e serviços básicos. Nesta crise econômica internacional nós descobrimos, também, que as políticas sociais ajudaram o Brasil a enfrentar o problema de cabeça erguida.

Outra dicotomia empobrecedora que estamos vivendo hoje diz respeito à questão ambiental. Econômico, social ou ambiental? Proponho que coloquemos tudo em termos de desenvolvimento integral e integrado. Temos de trabalhar na perspectiva do desenvolvimento econômico, do desenvolvimento político (que fortalece as instituições políticas democráticas e isso tem impacto em várias outras áreas), do desenvolvimento social, do desenvolvimento ambiental e do desenvolvimento cultural. Tudo isso na perspectiva da sustentabilidade e do desenvolvimento regional, respeitando nossas vocações.

\section{Compromisso com futuro}

Não só nosso olhar para a história nos indica o quanto conseguimos avançar. Os resultados recentes das políticas sociais, com o impacto no desenvolvimento do país e nas mudanças de paradigmas, mostram que estamos no caminho certo. Podemos dizer que hoje somos desassombrados, tanto na acepção original da palavra, de que estamos superando nossas sombras, que estamos jogando luz sobre nossos caminhos, quanto no sentido figurado, de que estamos nos tornando mais fortes, corajosos e ousados.
É nesse ponto que se apresentam nossos desafios. Alguns foram tratados neste artigo, mas ainda há outros que consideramos fundamentais. Destacamos pelo menos quatro. Um deles é o desafio da gestão da informação. Para manter, aperfeiçoar e ampliar nossas políticas, temos de ter monitoramento, avaliação dos programas e de ações. Temos de estabelecer prioridades, trabalhar com prazos, com metas, estabelecer procedimentos claros. Nesse sentido, o Ministério do Desenvolvimento Social e Combate à Fome incorporou a Secretaria de Avaliação e Gestão da Informação (SAGI), que cumpre um papel fundamental na organização das nossas políticas, cria mecanismos de aperfeiçoamento de gestão, trabalha com resultados, avaliação, pesquisas e monitoramento.

Como desdobramento dessa questão, temos o desafio do planejamento. Por isso é fundamental que a gente trabalhe com resultados, que tenhamos critérios e metas estabelecidos de maneira bastante objetiva. Precisamos saber onde queremos chegar, em quanto tempo, o que falta para alcançar a meta e quais os motivos que nos estão impedindo de alcançá-la.

Isso faz parte da dimensão do nosso compromisso com a transparência. Sabemos que dependemos de recursos e dinheiro não cai do céu. $O$ dinheiro vem da sociedade e, sobretudo, do sofrido bolso da classe média e dos pobres que pagam impostos embutidos, indiretos. É essencial que as pessoas saibam onde está sendo aplicado o dinheiro público, pois a corrupção é inaceitável. Mas temos de ter compreensão de que corrupção não é só roubar. Para esse caso, gravíssimo, de polícia, temos de trabalhar com repressão. Mas corrupção é também não fiscalizar, é permitir o desperdício, não acompanhar. 
O compromisso com a transparência tem de permitir que o cidadão saiba não só onde, mas também como está sendo aplicado o dinheiro público. Além disso, é fundamental que as pessoas possam saber quais são os resultados de tais investimentos, quais são os benefícios diretos e indiretos dos programas sociais.

Outro desafio, o terceiro, é a questão $\mathrm{da}$ intersetorialidade, que tem reflexo direto na vida das pessoas, mas também tem efeito na administração pública, porque promove racionalização dos recursos, estabelece sinergias e torna as ações menos dispendiosas. Se a gente pega os manuais de políticas sociais, de políticas públicas, todo mundo é a favor da intersetorialidade, desde que seja sob o comando do seu ministério. A equipe da Educação acha que é da Educação, a Saúde acha que é ela, nós achamos que somos nós, e por aí vai. Isso é natural, se consideramos que a cabeça pensa onde o cérebro está. Mas temos de avançar. Transcender, ir além do nosso lugar, é um exercício, é uma ascese mental, intelectual e até mesmo emocional, porque implica em sair do lugar, em ver o outro, em abrir mão do poder, no sentido de integrar com outras pessoas. Por isso, é um processo de crescimento que exige um grande esforço de aprendizagem.

Por conta dessa questão, penso que a psicologia deve ser muito aplicada nos cursos de capacitação e de formação, para ajudar a melhorar a gestão. A psicologia tem uma importante contribuição para ajudar a promover a mudança das pessoas, quebrar resistências que impedem o diálogo. Podemos desenvolver, com a ajuda da psicologia, a dimensão da autocrítica, do autoconhecimento, fundamental para estabelecer trabalhos em equipe. Afinal, com frequência transferimos nossas limitações para outros e é fundamental que as pessoas sejam capazes de fazer autoavaliação e assumir limitações e eventuais falhas.

Temos de considerar, ainda, que o tema da intersetorialidade encontra um espaço muito fértil de trabalho, que é o da territorialidade. Esse foi um tema do Simpósio Internacional de Desenvolvimento Social, organizado pelo MDS no ano passado. $\mathrm{Na}$ ocasião, o ex-presidente Lula, que participou da abertura e do encerramento do evento, captou essa questão com agilidade e deixou uma mensagem bem forte para que pensássemos a questão da territorialidade na área urbana. $\mathrm{Na}$ área rural, temos uma experiência com o Ministério de Desenvolvimento Agrário, um ministério irmão, muito integrado conosco, que são os Territórios da Cidadania, uma proposta de articulação de programas sociais em áreas rurais da região do semiárido brasileiro. Penso que devemos assumir o desafio de planejar políticas territoriais nas cidades, especialmente na periferia, nas áreas pobres das grandes cidades, das regiões metropolitanas, e expandindo para as médias cidades e pequenas, até fazer o encontro dos territórios da cidadania da área rural.

Nas áreas conflagradas, onde está posta a questão da violência, das forças da dissolução e da desconstituição, há ali a presença do Estado. O Estado Nacional, os estados membros, as unidades federadas e os municípios estão lá. Há a delegacia de polícia, o destacamento policial, a escola, o posto de saúde, o médico da família, os agentes de saúde da família, os CRAS e CREAS, campo de futebol, área esportiva, equipamento cultural. Nem todos os equipamentos estão no mesmo lugar, na mesma região, mas eles se fazem presentes. Só que esses equipamentos, esses gestores, agentes públicos, não conversam. 
Eles não estabelecem uma relação para constituir as forças da vida, para contrapor as forças da morte, da desconstituição, às forças do bem, da possibilidade, da construção. Certamente, temos de pensar as ações de prevenção e combate direto à criminalidade. Mas não vamos ganhar essa guerra só na violência. Você ganha também no coração e nas mentes das pessoas. Temos de levar as nossas políticas públicas, mostrar presença, eficácia, articular as políticas a partir da integração dos gestores, dos agentes e dos equipamentos, e também das forças vivas da comunidade. Toda comunidade, por mais sofrida que seja, tem presenças positivas, tem igrejas, tem movimento social, tem militantes, tem movimento de mulheres, grupo de mães, movimento de jovens.

Por último, mas não em hierarquia de importância, a questão das nossas crianças. Precisamos continuar cuidando dos jovens: a política da juventude é fundamental e temos o Pró-Jovem Adolescente, o PETI, o Sentinela (estratégia de combate à violência e exploração sexual de crianças e adolescentes). Precisamos cuidar das famílias, aperfeiçoar cada vez mais o Bolsa Família e os outros programas. Estou impressionado com a importância das políticas voltadas para a criança. O Ministério da Educação está fazendo um belo trabalho, mas acredito que ainda podemos ousar mais e essa é uma responsabilidade não só do governo, mas de todo o Estado brasileiro e, nesse sentido, incluindo os governos estaduais, municipais, a sociedade civil, empresários, organizações não governamentais.

Estamos trabalhando uma proposta de ampliar a educação infantil a partir dos quatro anos até 2016. Isso é importante. Mas fico pensando: o que temos para oferecer às crianças entre zero e quatro anos? Enquanto essa criança não tem creche, não tem lugar para ir, não tem escola de qualidade, o que as mães fazem com eles? A mãe tem de trabalhar. Quanto mais pobre, mais precisa trabalhar. Defendo que quanto mais pobre, maior tem de ser o investimento para cuidar das crianças. Para as comunidades mais pobres, as melhores escolas infantis; nas comunidades mais pobres, as melhores creches, do ponto de vista de equipamento, de prédio, de recursos, de professor. Fazer na educação infantil, em um contexto integrado com as políticas sociais, o que fizemos para acabar com a fome no Brasil.

Isto é anunciador: nós, de fato, estamos acabando com a fome no Brasil. Graciliano Ramos não escreveria mais Vidas Secas, pelo menos não como retrato da sociedade brasileira. Já não teria um Fabiano. Os Fabianos estão desaparecendo no Brasil. No caso do Bolsa Família, a maior parte do dinheiro vai para comida, como mostrou uma pesquisa que fizemos: $93 \%$ das crianças dessas famílias estão tendo três refeições por dia. Penso que é possível fazer uma ação desse nível com as crianças e não seria uma meta exclusivamente de educação, mas um trabalho que colocasse a criança no centro de um conjunto de ações.

É necessário concentrar todas as ações, de alimentação, de assistência social, de educação, de saúde, enfim, direcionar tudo para a gente salvar uma geração. Penso que é muito mais difícil fazer esse trabalho quando já perdemos algumas referências importantes. Porque, sejamos claros, depois que alguém chega ao ponto de se tornar um consumidor compulsivo de drogas, de estabelecer uma relação de dependência com o álcool, ou de se prostituir, fica muito mais difícil. Ainda há espaço para recuperação. Este é dos nossos compromissos mais urgentes. Mas é uma tarefa dura, temos de disputar um por um, luta a luta. 
Por isso, acredito que precisaríamos de um esforço de salvar uma geração inteira no Brasil. Temos de cuidar das crianças que estão nascendo agora e falar que vamos tomar conta desses meninos. E quanto mais pobre, mais o Estado tem de estar presente, mais tem de cuidar.

Os desafios são muitos e poderíamos prosseguir nas muitas possibilidades que temos de construir. Mas penso que, no espaço deste texto, conseguimos reunir um bom material para reflexão, embora ele ainda precise ser desdobrado em conversas futuras. Este artigo se inscreve justamente neste propósito: dar uma modesta contribuição para nossa extensa pauta de construir uma administração pública mais eficiente e eficaz, que provoque os melhores sentimentos de nossa gente e esteja em sintonia com um projeto de Nação. Conseguimos construir um belo ponto de partida. Mas temos de continuar a enfrentar os desafios para estarmos à altura de nossas melhores conquistas. E sinto que estamos fazendo isso. Desassombrados que somos.

(Artigo adaptado da palestra do ex-ministro Patrus Ananias na ENAP, em março de 2010. Versão final em junho de 2010.)

\section{Notas}

* Este artigo é uma versão adaptada da palestra do ex-ministro Patrus Ananias proferida na abertura do Curso de Especialização de Políticas Públicas de Proteção e Desenvolvimento Social, em 16 de março de 2010, na Escola Nacional de Administração Pública (ENAP). Na ocasião, Patrus Ananias era ministro do Desenvolvimento Social e Combate à Fome. Ele se exonerou do cargo em 30 de março.

${ }^{1}$ Ver Varnhagen, Francisco Adolfo. História Geral do Brasil (5 v.). $5^{a}$ ed. Revisão e notas de Rodolfo Garcia. São Paulo, Editora Melhoramentos, 1956.

${ }^{2}$ Ver Nabuco, Joaquim. Minha Formação. Brasília: Senado Federal, 1998. Disponível em: http:/ / www.dominiopublico.gov.br. Acesso em 17 de maio de 2009. Nabuco, Joaquim, 2002, O abolicionismo, em Silviano Santiago, Intérpretes do Brasil, volume I, Rio de Janeiro, Nova Aguilar.

${ }^{3}$ Ver CunHA, Euclides da. Os Sertões. Rio de Janeiro, Ediouro, 2009. 


\section{Resumo-Resumen-Abstract}

\section{Gestão pública: desassombrando nossa história}

Patrus Ananias

O desafio da gestão pública no Brasil faz parte de um acerto de contas com nossa história. Integra um conjunto de esforços para romper com um déficit histórico de gestão que por longos anos comprometeu o desenvolvimento das extraordinárias possibilidades no Brasil, dentro de um contexto mais amplo de problemas econômicos e sociais. Neste artigo, propõe-se uma reflexão sobre esse histórico, apontando como a relação promíscua entre público e privado alimentou um quadro de exclusão social que está sendo revertido e discutindo o papel da qualificação da gestão pública nesse processo.

Palavras-chave: gestão pública - público/privado - política social

\section{Gestión pública: Aclarando nuestra historia}

Patrus Ananias

El reto de la gestión pública en Brasil hace parte de un ajuste de cuentas con nuestra historia. Integra un conjunto de esfuerzos que hemos hecho para romper con un déficit histórico de gestión, que por largos años comprometió el desarrollo de las extraordinarias posibilidades brasileñas, en un contexto más amplio de problemas económicos y sociales. En este artículo, propongo una reflexión del histórico, señalando como la relación promiscua entre público y privado alimentó un cuadro de exclusión social que estamos consiguiendo cambiar, y discutiendo el papel de la cualificación de la gestión pública en el proceso.

Palabras clave: gestión pública, público-privado, política social

\section{Public management: demystifying our history}

Patrus Ananias

The challenge of public management in Brazil is part of a setting of scores with our history. Integrates a number of efforts to break with a historic deficit of management for many years undertook the development of extraordinary possibilities in Brazil within a broader context of economic and social problems. This article proposes a reflection on this historical, pointing out how the promiscuous relation between public and private fed a situation of social exclusion that is being reversed by discussions about the role of public management skills in this process.

Keywords: public management-public/private - social policy

Graduado em Direito, tem especialização em Poder Legislativo e mestrado em Direito Processual. É doutorando em Filosofia, Tecnologia e Sociedade pela Universidad Complutense de Madrid. Foi prefeito de Belo Horizonte (1993-1996) e em 2002 elegeu-se deputado federal. De 2004 a março de 2010, foi ministro do Desenvolvimento Social e Combate à Fome. Contato: patrusananias@terra.com.br 